\title{
Associations between lower extremity muscle mass and metabolic parameters related to obesity in Japanese obese patients with type 2 diabetes
}

Hidetaka Hamasaki, Yu Kawashima, Hiroki Adachi, Sumie Moriyama, Hisayuki Katsuyama, Akahito Sako, Hidekatsu Yanai

Background. Age-related loss of muscle mass (sarcopenia) increases the incidence of obesity in the elderly by reducing physical activity. This sarcopenic obesity may become self-perpetuating, increasing the risks for metabolic syndrome, disability, and mortality. We investigated the associations of two sarcopenic indices, the ratio of lower extremity muscle mass to body weight (L/W ratio) and the ratio of lower extremity muscle mass to upper extremity muscle mass (L/U ratio), with metabolic parameters related to obesity in patients with type 2 diabetes and obesity. Methods. Of 148 inpatients with type 2 diabetes treated between October 2013 and April 2014, we recruited 26 with obesity but no physical disability. Daily physical activity was measured by a triaxial accelerometer during a period of hospitalization, and which was also evaluated by our previously reported non-exercise activity thermogenesis questionnaire. We measured body composition by bioelectrical impedance and investigated the correlations of L/W and L/U ratios with body weight, body mass index (BMI), waist circumference (WC), waist-to-hip ratio (WHR), visceral fat area, subcutaneous fat area, serum lipid profile, and daily physical activity. Results. The L/W ratio was significantly and negatively correlated with BMI, WC, WHR, body fat mass, body fat percentage, subcutaneous fat area, and serum free fatty acid concentration, was positively correlated with daily physical activity: the locomotive nonexercise activity thermogenesis score, but was not correlated with visceral fat area. The L/U ratio was significantly and positively correlated with serum high-density lipoprotein cholesterol. Conclusions. High L/W and L/U ratios, indicative of relatively preserved lower extremity muscle mass, were predictive of improved metabolic parameters related to obesity. Preserved muscle fitness in obesity, especially of the lower extremities, may prevent sarcopenic obesity and lower associated risks for metabolic syndrome and early mortality. 
2 Associations between lower extremity muscle mass and metabolic parameters

3 related to obesity in Japanese obese patients with type 2 diabetes

4

5 Hidetaka Hamasaki ${ }^{1,2}$, Yu Kawashima ${ }^{1}$, Hiroki Adachi $^{1}$, Sumie Moriyama ${ }^{1}$, Hisayuki Katsuyama ${ }^{1}$,

6 Akahito Sako ${ }^{1}$ and Hidekatsu Yanai ${ }^{1}$

7

$8{ }^{1}$ Department of Internal Medicine, National Center for Global Health and Medicine Kohnodai Hospital,

9 Chiba, Japan

$10{ }^{2}$ General Internal Medicine, Community Healthcare Studies, Jichi Medical University Graduate School,

11 Tochigi, Japan

12

13

14 Corresponding author

15 Hidetaka Hamasaki, Department of Internal Medicine, National Center for Global Health and Medicine

16 Kohnodai Hospital, 1-7-1 Kohnodai, Chiba 272-8516, Japan; E-mail: hhamasaki78@gmail.com; TEL:

$17+810473723501$; FAX: +81 0473721858

18

19 


\section{BACKGROUND}

21 Excess body weight is a serious public health problem and its prevalence has been increasing steadily

22 since 1980 (Finucane et al., 2011). Recommendations to treat obesity by physical activity have 23 emphasized aerobic exercise rather than resistance training (Donnelly et al., 2003; Haskell et al., 2007)

24 because it has been assumed that aerobic exercise results in greater energy expenditure. However, the 25 maintenance of a large muscle mass by resistance training has also been reported to improve cardiovascular disease (CVD) risk factors such as dyslipidemia and type 2 diabetes (Hurley et al., 2011; Braith et al., 2006; Williams et al., 2007) and a recent meta-analysis suggested that resistance training is effective for improving glycemic control in type 2 diabetes (Strasser et al., 2010).

Sarcopenia is an age-related condition characterized by loss of skeletal muscle mass and decreased muscle strength (Evans, 1995). The prevalence of obesity increases in elderly people with sarcopenia. Sarcopenia is often associated with obesity. Such combination of muscle mass decline and excess adiposity is defined as sarcopenic obesity, which increases the risks for disability and mortality (Zamboni et al., 2008; Prado et al., 2012). Additionally, diabetic older men have significantly lower muscle strength than those without diabetes (Sayer et al., 2005), suggesting that diabetes is an independent risk factor for sarcopenia.

To prevent sarcopenia, it is important to increase muscle mass and strength by resistance training. In elderly people, fat-free mass, especially muscle mass decreased and unfavorable changes in body composition were observed (Buffa et al., 2011). Therefore, we should also treat obesity considering the age of patients. We hypothesized that reduced muscle mass in the lower extremities would be associated with a more sedentary lifestyle, which could lead to or exacerbate sarcopenia. The aim of this study was to investigate the associations of two indices of sarcopenia of the legs, namely, the ratio of lower extremity muscle mass to body weight (L/W ratio) and the ratio of lower extremity muscle mass to upper extremity muscle mass (L/U ratio), with parameters related to obesity, including body mass index (BMI), 
44 waist circumference (WC), waist-to-hip ratio (WHR), visceral fat area, subcutaneous fat area, body fat 45 mass, body fat percentage, and serum lipid profile. We also studied influences of age and sex on such 46 parameters.

47

48

49

50

51

52

53

54

55

56

57

58

59

60

61

62

63

64

65

66

67

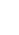
64

\section{METHODS}

\section{Study population}

Of 148 patients with type 2 diabetes admitted to our hospital for glycemic control between October 2013 and April 2014, we recruited 26 with BMI over $30.0 \mathrm{~kg} / \mathrm{m}^{2}$, the World Health Organization (WHO) definition of obesity (WHO, 2000). We excluded patients with physical disability such as osteoarthritis. These obese type 2 diabetes patients consisted of 10 men and 16 women, aged 27 to 76 years old. The study protocol was approved by the Medical Ethics Committee of the National Center for Global Health and Medicine (Reference No. NCGM-G-001562), and all subjects gave written informed consent to use their data in the study. This study was performed in accordance with the Declaration of Helsinki.

\section{Anthropometric measurements}

Height and weight were measured using a rigid stadiometer and calibrated scales (seca 764, seca Co., Ltd, Birmingham, United Kingdom). BMI was calculated as body weight in kilograms divided by the square of body height in meters. WC was measured at the umbilical level at the end of exhalation (Lohman et al., 1988), and hip circumference was measured at the level of the maximum extension of the buttocks posteriorly in the horizontal plane (Lohman et al., 1988).

\section{Body composition analysis}

66 Body composition was analyzed using a bioelectrical impedance analysis device (InBody720, Biospace 67 Co., Ltd, Tokyo, Japan). The method is based on the principle that lean body mass contains higher water 


(

and electrolyte content than fat tissue, so these tissues can be distinguished by electrical impedance. Segmental body composition was estimated using a patented 8-point tactile electrode system. The device uses 6 frequencies $(1,5,50,250,500$, and $1000 \mathrm{kHz})$ and produces 30 impedance values for five body segments: right and left upper extremities, trunk, and right and left lower extremities (Anderson et al., 2012). Previous validation study showed that both fat mass and lean body mass evaluated by this device were highly correlated with which measured by dual-energy X-ray absorptiometry (correlation coefficient $=0.832$ and 0.899 , respectively) (Faria et al., 2014).

\section{Abdominal fat tissue measurement}

Visceral and subcutaneous fat areas were measured using abdominal computed tomography (CT). This CT method was validated previously (Jensen et al., 1995). Single-slice imaging was performed at the umbilical level in a supine position at the end of exhalation using the Aquilion PRIME ${ }^{\mathrm{TM}} \mathrm{CT}$ system (Toshiba Medical Systems Co., Ltd, Tochigi, Japan). The imaging conditions were $120 \mathrm{kV}, 50 \mathrm{~mA}$, and slice thickness of $5 \mathrm{~mm}$. Visceral and subcutaneous fat areas were calculated using commercial software (Fat Measurement, Toshiba Medical Systems Co., Ltd).

\section{Blood examination}

Venous blood samples were taken after a 12-h overnight fast. Fasting plasma glucose was measured using an enzymatic method (GA-1170, Arkray, Inc., Kyoto, Japan). Hemoglobin A1c (HbA1c) was measured by high-performance liquid chromatography (HA-8180, Arkray, Inc.). Total cholesterol, total triglycerides (TG), and high-density lipoprotein cholesterol (HDL-C) were determined enzymatically using the commercially available kits T-CHO • KL (Sysmex, Co, Ltd., Hyogo, Japan), Pureauto S TG-N, and Cholestest N HDL (Sekisui Medical Co., Ltd., Tokyo, Japan), respectively. Low-density lipoprotein 
91 cholesterol (LDL-C) was calculated by the Friedewald formula (Friedwald et al., 1972). Free fatty acid 92 concentration (FFA) was measured enzymatically using the NEFA-SS Eiken kit (Eiken Chemical Co.,

93 Ltd, Tochigi, Japan)

94

95

96

97

98

99

100

101

102

103

104

105

106

107

108

109

110

111

112

113

114

\section{Physical activity measurements}

Physical activity measurements were performed by the method which we previously reported (Hamasaki et al., 2014). Briefly, daily physical activity was measured using a portable triaxial accelerometer during a period of hospitalization (Active Style Pro HJA-350IT, Omron Co., Ltd, Kyoto, Japan). This device differentiated 11 daily activities with almost 100\% accuracy (Oshima et al., 2010). Furthermore, metabolic equivalent values (METs) determined by triaxial accelerometry were strongly correlated with METs calculated from energy expenditure as measured by indirect calorimetry (Oshima et al., 2010; Ohkawara et al., 2011). Activity data were stored minute-by-minute and downloaded to a personal computer for analysis. Basal metabolic rate (BMR) was estimated from the following multiple regression equation: $\mathrm{BMR}(\mathrm{kcal} / \mathrm{day})=[(0.1283+0.0481 \times \mathrm{IBW}(\mathrm{kg})+0.0234 \times$ height $(\mathrm{cm})-0.0138 \times$ age $($ years $)$ - $0.5473 \times$ sex coefficient (man: 1, woman: 2)) × 293] (Ganpule et al., 2007). Total energy expenditure (TEE) was calculated by regression equation using the MET values obtained by triaxial accelerometry (Oshima et al., 2010). Physical activity level (PAL) was calculated as PAL = TEE / BMR (FAO/WHO/UNU, 1985).

Daily physical activity was also assessed using our previously reported non-exercise activity thermogenesis (NEAT) questionnaire (Hamasaki et al., 2013). Briefly, the questionnaire consists of 11 items about locomotive activities and 25 items about non-locomotive activities. We evaluated each item on a 3-point scale to quantify levels of daily physical activity and then summed the scores to determine the NEAT score. The validity of the NEAT questionnaire was evaluated by comparing scores with objectively measured physical activity levels under free conditions using triaxial accelerometry. 


\section{Statistical analysis}

117 All statistical analysis was performed using SPSS version 19 (IBM Co., Ltd, Chicago, USA). All values

118 are expressed as mean \pm standard deviation (SD). Sex differences in physiological and biochemical data

119 were analyzed by the Student's t test. Correlations of the $\mathrm{L} / \mathrm{W}$ ratio, L/U ratio and the ratio of upper 120 extremity muscle mass to body weight (U/W ratio) with age, BMI, WC, WHR, TG, HDL-C, LDL-C,

121 FFA, PAL and the locomotive NEAT score were assessed using Pearson's correlation coefficient.

122 Multiple regression analysis was performed to test the independent correlations of $\mathrm{L} / \mathrm{W}$ and $\mathrm{L} / \mathrm{U}$ ratios

123 with physical and biochemical data. Models were adjusted for age. We divided participants into higher

124 and lower BMI groups by the median BMI $\left(\geq 35.9 \mathrm{~kg} / \mathrm{m}^{2}\right.$ and $\left.<35.9 \mathrm{~kg} / \mathrm{m}^{2}\right)$. Differences in age, the L/W,

$125 \mathrm{~L} / \mathrm{U}$ and $\mathrm{U} / \mathrm{W}$ ratios and the locomotive NEAT score between the higher and lower BMI groups were 126 analyzed by the Student's t test. A $p$ value less than 0.05 was considered statistically significant.

\section{RESULTS}

129 The mean age of subjects was $50.7 \pm 13.2$ years. The mean BMI of subjects was $36.2 \pm 4.7 \mathrm{~kg} / \mathrm{m}^{2}$. Eleven

130 subjects were obese class I, 8 were obese class II, and 7 were obese class III (WHO, 2000). About $70 \%$

131 of the subjects $(18 / 26)$ were never smokers, however, 2 subjects were current smokers and 6 subjects

132 were ex-smokers. Two patients were untreated, 17 patients were treated with oral hypoglycemic agents

133 and 7 patients were treated with combination of oral hypoglycemic agents and insulin. Height, weight,

134 WHR, skeletal muscle mass, the L/W and L/U ratio were significantly higher in men than in women.

135 However, age, serum HDL-C and body fat percentage were significantly higher in women than in men.

136 These results are showed in Table 1. Age was not significantly correlated with L/W, U/W and L/U ratios.

137 The L/W ratio was negatively correlated with BMI, WC, serum FFA, subcutaneous fat area, body fat 
138 mass, and body fat percentage, but was not significantly correlated with PAL. However, L/W ratio was

139 significantly and positively correlated with the locomotive NEAT score. The U/W ratio was positively

140 correlated with WHR and was negatively correlated with serum HDL-C, FFA and body fat percentage.

141 The L/U ratio was negatively correlated with weight, BMI, WC, and WHR and was positively associated

142 with serum HDL-C. These results are summarized in Table 2. After adjustment for age, L/W ratio was 143 negatively associated with BMI $(\beta=-0.53, p=0.006)$, WC $(\beta=-0.539, p=0.005)$, serum FFA $(\beta=-$

$1440.425, p=0.029)$, subcutaneous fat area $(\beta=-0.678, p<0.001)$, body fat mass $(\beta=-0.623, p=0.001)$

145 and body fat percentage $(\beta=-0.896, p<0.001)$, and positively associated with the locomotive NEAT

$146 \operatorname{score}(\beta=7.02, p<0.001)$. After adjustment for age, $\mathrm{L} / \mathrm{U}$ ratio was also negatively associated with weight

$147(\beta=-0.441, p=0.036), \mathrm{BMI}(\beta=-0.484, p=0.013), \mathrm{WC}(\beta=-0.499, p=0.011)$ and $\mathrm{WHR}(\beta=-0.727$,

$148 p<0.001)$, and positively associated with serum HDL-C $(\beta=0.542, p=0.006)$. No significant

149 association was found between the L/U ratio and visceral fat area, subcutaneous fat area, body fat mass,

150 or body fat percentage. In men, The L/W ratio was negatively correlated with BMI, WC, subcutaneous

151 fat area, body fat mass, and body fat percentage. However, in women, L/W ratio was negatively

152 correlated with only body fat percentage and was positively correlated with the locomotive NEAT score.

153 The $\mathrm{L} / \mathrm{U}$ ratio was negatively correlated with $\mathrm{WC}$ and $\mathrm{WHR}$ in men. The $\mathrm{L} / \mathrm{U}$ ratio was also negatively

154 correlated with BMI and WHR in women. Moreover, L/U ratio was positively correlated with serum

155 HDL-C. Table 3 showed these single correlations of $\mathrm{L} / \mathrm{W}$ ratio, $\mathrm{U} / \mathrm{W}$ ratio and $\mathrm{L} / \mathrm{U}$ ratio with clinical

156 parameters.

157 We also examined the differences in age, sex ratio, $\mathrm{L} / \mathrm{W}, \mathrm{U} / \mathrm{W}$ and $\mathrm{L} / \mathrm{U}$ ratios, and the locomotive NEAT

158 score between the higher BMI group $\left(\geq 35.9 \mathrm{~kg} / \mathrm{m}^{2}\right)$ and lower BMI group $\left(<35.9 \mathrm{~kg} / \mathrm{m}^{2}\right)$. Both L/W

159 and $\mathrm{L} / \mathrm{U}$ ratios were significantly lower in the higher BMI group than in the lower BMI group.

160 Furthermore, the locomotive NEAT score was also significantly lower in the higher BMI group (Table

161 5). On the contrary, no differences in age, sex ratio and PAL were observed between the higher and lower 
162

163

164

165

166

167

168

169

170

171

172

173

174

175

176

177

178

179

180

181

182

183

184

185 Lower extremity muscle mass and age

BMI groups.

\section{DISCUSSION} factors for metabolic disease and early mortality. diabetes patients.

Numerous studies have suggested that moderate regular aerobic exercise can lead to weight loss, fat mass loss, and improved insulin sensitivity in obesity (McTiernan et al., 2007; Houmard et al., 2004). Resistance training has also been shown effective for improving metabolic risk factors, including insulin resistance and dyslipidemia (Braith et al., 2006); however, the extent to which resistance training can improve metabolic risk factors and the mechanism involved are still unclear. We found that lower extremity muscle mass was a critical determinant of favorable metabolic status in obese type 2 diabetes patients, implying that maintaining leg muscle strength through resistance training may help reduce risk

Several previous studies reported an inverse association between muscle strength and metabolic risks (Steene-Johannessen et al., 2009; Jurca et al., 2005). Obesity increases intramyocellular TG in skeletal muscle, which impairs insulin sensitivity and decreases muscle strength (Amati et al., 2011; Kelley, 2002). Accordingly, resistance training for improving muscle fitness should be performed to prevent or improve metabolic risk factors such as insulin resistance and dyslipidemia.

In the present study, higher L/W and L/U ratios were associated with favorable BMI, WC, WHR, serum FFA, and serum HDL-C. In addition, both L/W and L/U ratios were lower (i.e., lower extremity muscle mass was reduced) in patients with higher BMI. On the other hand, higher U/W ratio was associated with unfavorable WHR and serum HDL-C. These results strongly suggest that not upper extremity but adequate lower extremity muscle mass is critical for reducing metabolic risk factors in obese type 2 
186 Sarcopenia is an age-related condition characterized by loss of skeletal muscle mass (Evans, 1995).

187 Lower extremity muscle mass will decrease with age. However, no significant correlations between L/W 188 or $\mathrm{L} / \mathrm{U}$ ratios and age were observed in this study. After adjustment for age, associations of $\mathrm{L} / \mathrm{W}$ and $\mathrm{L} / \mathrm{U}$ 189 ratios with favorable metabolic values remained. Although we cannot always generalize our results to 190 the general population, L/W and L/U ratios may be useful indicators of lower extremity muscle mass in 191 wide range of age groups.

192

193 Lower extremity muscle mass and daily physical activity

194 Obese patients tend to have a sedentary lifestyle, which increases body weight and decreases muscle 195 mass and strength in the lower extremities, and these in turn contribute to a continued sedentary lifestyle.

196 The locomotive NEAT score was in fact significantly reduced in the higher BMI group, suggesting that

197 the most obese individuals tended not to walk as often as subjects in the lower BMI group. We also 198 observed a significant and positive correlation between the L/W ratio and the locomotive NEAT score, 199 suggesting that increased locomotive activity is associated with increased muscle mass. While we did 200 not find significant correlations of PAL with the $\mathrm{L} / \mathrm{W}$ and $\mathrm{L} / \mathrm{U}$ ratios, PAL was measured during a period 201 of hospitalization and so these findings may not represent the true physical activity of subjects in daily 202 life outside the hospital.

\section{Lower extremity muscle mass and lipid metabolism}

205 Free fatty acid levels are usually elevated in obese patients because the enlarged adipose tissue releases 206 FFA and FFA clearance is reduced (Boden, 2008). Elevated FFA levels cause insulin resistance in 207 skeletal muscle; indeed, high FFA levels are responsible for about 50\% of the insulin resistance in obese 208 patients with type 2 diabetes (Boden, 2008). Lowering FFA levels can improve insulin resistance. Leg 209 muscle is the predominant FFA uptake tissue, accounting for $15 \%$ to $20 \%$ of FFA uptake at rest and $30 \%$ 
210 to $60 \%$ during exercise (Jensen, 2003). Therefore, lower extremity muscle fitness and locomotive

211 activity are essential for maintaining proper FFA metabolism. A significant and negative correlation of

212 the L/W ratio with FFA levels suggests that increasing lower extremity muscle mass is associated with 213 improvement of FFA metabolism and insulin resistance in obese type 2 diabetes patients.

214 Dyslipidemia in obesity is typically characterized by elevated serum TG and FFA as well as lower HDL-

215 C with HDL dysfunction (Mineo et al., 2012). HDL metabolism is strongly impaired in obesity, which

216 increases CVD risk. However, Stensvold et al. (2010) found no significant association between dynamic

217 resistance training and HDL-C (Stensvold et al., 2010). In contrast, the significant and positive

218 correlation between the L/U ratio and HDL-C in the present study suggests that larger muscle mass of

219 the lower extremities has a favorable effect on lipid metabolism even without a resistance training

220 program. Moreover, higher HDL-C levels are associated with physical performance indices such as

221 walking speed (Landi et al., 2007), indicating that lower extremity muscle fitness has some associations

222 with increase of HDL-C levels. Why this association was found in the present study but not by Stensvold

223 et al. warrants further study given the strong link between HDL-C and CVD risk.

224 A systematic review and meta-analysis to investigate the independent and combined effects of aerobic

225 exercise and resistance training on visceral fat area showed that aerobic exercise was effective in

226 reducing visceral fat area, while resistance training was not (Ismail et al., 2012). However, Yagi et al

227 found that higher skeletal muscle mass of the lower limbs was associated with decreased visceral fat area

228 in healthy men, again suggesting the importance of locomotive activities for the control of obesity and

229 metabolic syndrome (Yagi et al., 2014). The exact reason why a negative correlation of L/W ratio with

230 visceral fat area was not observed is unclear. It may be related to that subcutaneous fat obesity is

231 dominant in our study population. Misra A et al. showed that moderate intensity resistance training

232 reduced subcutaneous adipose tissue in patients with type 2 diabetes (Misra et al, 2008), which suggests

233 that resistance training can reduce subcutaneous fat but not visceral fat in patients with type 2 diabetes. 
234 Indeed, we found significant and negative correlations of the L/W ratio with WC, body fat mass, body

235 fat percentage, and subcutaneous fat area, suggesting that increasing lower extremity muscle mass can 236 lead to a reduction in fat mass.

\section{Sex differences}

239 In the present study, we observed more significant correlations of $\mathrm{L} / \mathrm{W}$ and $\mathrm{L} / \mathrm{U}$ ratios with metabolic 240 parameters related to obesity in men than in women. On the other hand, L/U ratio was positively 241 correlated with serum HDL-C in women not in men. However, the potential mechanism of sex 242 differences is unknown. Further studies are needed to elucidate the differences in the role of lower 243 extremity muscle mass between men and women.

\section{Limitations}

Limitations to our study include the cross-sectional study design, small sample size, and potential confounding factors. The cross-sectional study design does not allow causal relationships to be deduced, and future prospective studies are therefore needed to confirm our results. We recruited obese patients 250 according to WHO definition of obesity, with BMI over $30.0 \mathrm{~kg} / \mathrm{m}^{2}$, however, obesity was defined as a 251 BMI over $25.0 \mathrm{~kg} / \mathrm{m}^{2}$ in Japanese population (Examination Committee of Criteria for 'Obesity Disease' in Japan; Japan Society for the Study of Obesity. 2002). We should include such overweight patients in 253 a future study. In addition, about $70 \%$ of the participants (18/26) were currently taking cholesterol254 lowering agents such as statins and fibrates, which are known to increase HDL-C levels. Third, we did 255 not evaluate muscle strength of the lower extremities. However, a positive correlation between muscle 256 mass and muscle strength is well established (Janssen et al., 2000; Newman et al., 2003; Chen et al., 
258 represent the true physical activity of subjects in daily life outside the hospital.

260 Conclusions

261 We demonstrated that lower extremity muscle mass is predictive of reduced body weight, BMI, WC,

262 WHR, subcutaneous fat area, body fat mass, body fat percentage, and serum FFA as well as higher serum

263 HDL-C in obese patients with type 2 diabetes. Our results suggest that lower extremity muscle mass is

264 more important than upper extremity muscle mass for improving metabolic risk factors. Resistance

265 training targeting the lower extremities may allow obese patients to increase physical activity, preventing 266 sarcopenic obesity and concomitant risks of morbidity and mortality.

268 Acknowledgments

269 This work was supported in part by Grants-in-Aid for Research from the National Center for Global

270 Health and Medicine (26A-201).

271 Competing interests

272 The authors declare that they have no competing interests. 


\section{REFERENCES}

1 Amati F, Dubé JJ, Alvarez-Carnero E, Edreira MM, Chomentowski P, Coen PM, Switzer GE,

276 Bickel PE, Stefanovic-Racic M, Toledo FG, Goodpaster BH. 2011. Skeletal muscle triglycerides, 277 diacylglycerols, and ceramides in insulin resistance: another paradox in endurance-trained athletes? Diabetes 60:2588-2597.

2 Anderson LJ1, Erceg DN, Schroeder ET. 2012. Utility of multifrequency bioelectrical impedance 280 compared with dual-energy x-ray absorptiometry for assessment of total and regional body 281 composition varies between men and women. Nutr Res 32:479-485.

2823 Boden G. 2008. Obesity and free fatty acids. Endocrinol Metab Clin North Am 37:635-646.

2834 Braith RW, Stewart KJ. 2006. Resistance exercise training: its role in the prevention of 284 cardiovascular disease. Circulation 113:2642-2650. $286 \quad$ Antropol 35:259-265.

Chen L, Nelson DR, Zhao Y, Cui Z, Johnston JA. 2013. Relationship between muscle mass and 291 Fennessey PV, Sonko B, Sharp T, Jakicic JM, Blair SN, Tran ZV, Mayo M, Gibson C, 292 Washburn RA. 2003. Effects of a 16-month randomized controlled exercise trial on body weight and composition in young, overweight men and women: the Midwest Exercise Trial. Arch Intern Med 163:1343-1350.

2958 Evans WJ. 1995. What is sarcopenia? J Gerontol A Biol Sci Med Sci 50:5-8.

2969 Examination Committee of Criteria for 'Obesity Disease' in Japan; Japan Society for the 297 Study of Obesity. 2002. New criteria for 'obesity disease' in Japan. Circ J 66:987-992. 
29810 FAO/WHO/UNU. 1985. Energy and protein requirements. Report of a joint FAO/WHO/UNU 299 Expert Consultation. World Health Organ Tech Rep Ser 724:1-206.

30011 Faria SL, Faria OP, Cardeal MD, Ito MK. 2014. Validation study of multi-frequency bioelectrical 301 impedance with dual-energy X-ray absorptiometry among obese patients. Obes Surg 24:1476-1480.

30212 Finucane MM, Stevens GA, Cowan MJ, Danaei G, Lin JK, Paciorek CJ, Singh GM, Gutierrez 303 HR, Lu Y, Bahalim AN, Farzadfar F, Riley LM, Ezzati M; Global Burden of Metabolic Risk 304 Factors of Chronic Diseases Collaborating Group (Body Mass Index). 2011. Global Burden of 305 Metabolic Risk Factors of Chronic Diseases Collaborating Group (Body Mass Index). National, 306 regional, and global trends in body-mass index since 1980: systematic analysis of health examination 307 surveys and epidemiological studies with 960 country-years and 9·1 million participants. Lancet $308 \quad 377: 557-567$.

30913 Friedewald WT, Levy RI, Fredrickson DS. 1972. Estimation of the concentration of low-density 310 lipoprotein cholesterol in plasma, without use of the preparative ultracentrifuge. Clin Chem 18:499311502.

31214 Ganpule AA, Tanaka S, Ishikawa-Takata K, Tabata I. 2007. Interindividual variability in 313 sleeping metabolic rate in Japanese subjects. Eur J Clin Nutr 61:1256-61.

31415 Hamasaki H, Yanai H, Kakei M, Noda M, Ezaki O. 2014. The validity of the non-exercise activity 315 thermogenesis questionnaire evaluated by objectively measured daily physical activity by the triaxial 316 accelerometer. BMC Sports Sci Med Rehabil 6:27.

31716 Hamasaki H, Yanai H, Mishima S, Mineyama T, Yamamoto-Honda R, Kakei M, Ezaki O, 318 Noda M. 2013. Correlations of non-exercise activity thermogenesis to metabolic parameters in 319 Japanese patients with type 2 diabetes. Diabetol Metab Syndr 5:26.

32017 Haskell WL, Lee IM, Pate RR, Powell KE, Blair SN, Franklin BA, Macera CA, Heath GW, 321 Thompson PD, Bauman A; American College of Sports Medicine; American Heart 
Association. 2007. Physical activity and public health: updated recommendation for adults from the American College of Sports Medicine and the American Heart Association. Circulation 116:10811093.

18 Houmard JA, Tanner CJ, Slentz CA, Duscha BD, McCartney JS, Kraus WE. 2004. Effect of the volume and intensity of exercise training on insulin sensitivity. J Appl Physiol (1985) 96:101106.

Hurley BF, Hanson ED, Sheaff AK. 2011. Strength training as a countermeasure to aging muscle and chronic disease. Sports Med 41:289-306.

20 Ismail I, Keating SE, Baker MK, Johnson NA. 2012. A systematic review and meta-analysis of the effect of aerobic vs. resistance exercise training on visceral fat. Obes Rev 13:68-91.

21 Janssen I, Heymsfield SB, Wang ZM, Ross R. 2000. Skeletal muscle mass and distribution in 468 men and women aged 18-88 yr. J Appl Physiol (1985) 89:81-88.

22 Jensen MD, Kanaley JA, Reed JE, Sheedy PF. 1995. Measurement of abdominal and visceral fat with computed tomography and dual-energy x-ray absorptiometry. Am J Clin Nutr 61:274-278.

23 Jensen MD. 2003. Fate of fatty acids at rest and during exercise: regulatory mechanisms. Acta Physiol Scand 178:385-390.

24 Jurca R, Lamonte MJ, Barlow CE, Kampert JB, Church TS, Blair SN. 2005. Association of muscular strength with incidence of metabolic syndrome in men. Med Sci Sports Exerc 37:18491855.

25 Kelley DE. 2002. Skeletal muscle triglycerides: an aspect of regional adiposity and insulin resistance. Ann N Y Acad Sci 967:135-145.

26 Landi F, Russo A, Cesari M, Pahor M, Bernabei R, Onder G. 2007. HDL-cholesterol and physical performance: results from the ageing and longevity study in the sirente geographic area (ilSIRENTE Study). Age Ageing 36:514-520. 
34627 Lohman TG, Roche AF, Martorell R. 1988. Anthropometric Standardization Reference Manual.

347 Champaign, IL : Human Kinetics Books.

34828 Matsushita Y, Tomita K, Yokoyama T, Mizoue T. 2010. Relations between waist circumference $349 \quad$ at four sites and metabolic risk factors. Obesity (Silver Spring) 18:2374-2378.

350

351

30

McTiernan A, Sorensen B, Irwin ML, Morgan A, Yasui Y, Rudolph RE, Surawicz C, Lampe JW, Lampe PD, Ayub K, Potter JD. 2007. Exercise effect on weight and body fat in men and women. Obesity 15:1496-1512.

Mineo C, Shaul PW. 2012. Novel biological functions of high-density lipoprotein cholesterol. Circ Res 111:1079-1090.

31 Misra A, Alappan NK, Vikram NK, Goel K, Gupta N, Mittal K, Bhatt S, Luthra K. 2008. Effect of supervised progressive resistance-exercise training protocol on insulin sensitivity, glycemia, lipids, and body composition in Asian Indians with type 2 diabetes. Diabetes Care 31:1282-1287.

32 Newman AB, Haggerty CL, Goodpaster B, Harris T, Kritchevsky S, Nevitt M, Miles TP, Visser M; Health Aging And Body Composition Research Group. 2003. Health Aging And Body Composition Research Group. Strength and muscle quality in a well-functioning cohort of older adults: the Health, Aging and Body Composition Study. J Am Geriatr Soc 51:323-330.

33 Nordhamn K, Södergren E, Olsson E, Karlström B, Vessby B, Berglund L. 2000. Reliability of anthropometric measurements in overweight and lean subjects: consequences for correlations between anthropometric and other variables. Int J Obes Relat Metab Disord 24:652-657.

34 Ohkawara K, Oshima Y, Hikihara Y, Ishikawa-Takata K, Tabata I, Tanaka S. 2011. Real-time estimation of daily physical activity intensity by a triaxial accelerometer and a gravity-removal classification algorithm. Br J Nutr 105:1681-1691.

Oshima Y, Kawaguchi K, Tanaka S, Ohkawara K, Hikihara Y, Ishikawa-Takata K, Tabata I. 2010. Classifying household and locomotive activities using a triaxial accelerometer. Gait Posture 

31:370-374.

Prado CM, Wells JC, Smith SR, Stephan BC, Siervo M. 2012. Sarcopenic obesity: A critical appraisal of the current evidence. Clin Nutr 31:583-601.

37 Sayer AA, Dennison EM, Syddall HE, Gilbody HJ, Phillips DI, Cooper C. 2005. Type 2 diabetes, muscle strength, and impaired physical function: the tip of the iceberg? Diabetes Care 28:2541-2542.

38 Steene-Johannessen J, Anderssen SA, Kolle E, Andersen LB. 2009. Low muscle fitness is associated with metabolic risk in youth. Med Sci Sports Exerc 41:1361-1367.

39 Stensvold D, Tjønna AE, Skaug EA, Aspenes S, Stølen T, Wisløff U, Slørdahl SA. 2010. Strength training versus aerobic interval training to modify risk factors of metabolic syndrome. $J$ Appl Physiol (1985) 108:804-810.

Strasser B, Siebert U, Schobersberger W. 2010. Resistance training in the treatment of the metabolic syndrome: a systematic review and meta-analysis of the effect of resistance training on metabolic clustering in patients with abnormal glucose metabolism. Sports Med 40:397-415.

41 WHO. 2000. Obesity: preventing and managing the global epidemic. Report of a WHO consultation on obesity. World Health Organ Tech Rep Ser 894:1-253.

42 Williams MA, Haskell WL, Ades PA, Amsterdam EA, Bittner V, Franklin BA, Gulanick M, Laing ST, Stewart KJ; American Heart Association Council on Clinical Cardiology; American Heart Association Council on Nutrition, Physical Activity, and Metabolism. 2007. Resistance exercise in individuals with and without cardiovascular disease: 2007 update: a scientific statement from the American Heart Association Council on Clinical Cardiology and Council on Nutrition, Physical Activity, and Metabolism. Circulation 116:572-584.

43 Yagi S, Kadota M, Aihara K, Nishikawa K, Hara T, Ise T, Ueda Y, Iwase T, Akaike M, Shimabukuro M, Katoh S, Sata M. 2014. Association of lower limb muscle mass and energy 
394 expenditure with visceral fat mass in healthy men. Diabetol Metab Syndr 6:27.

39544 Zamboni M, Mazzali G, Fantin F, Rossi A, Di Francesco V. 2008. Sarcopenic obesity: a new 396 category of obesity in the elderly. Nutr Metab Cardiovasc Dis 18:388-395. 


\section{Table $\mathbf{1}$ (on next page)}

Clinical characteristics in men and women 
2 Table 1 Clinical characteristics in men and women

\begin{tabular}{llll}
\hline & & & \\
& & & \\
& & Women & Sex difference \\
\hline Age, years & $43.6(12.1)$ & $55.1(12.1)$ & 0.027 \\
Height, cm & $166.2(8.6)$ & $157.1(7)$ & 0.007 \\
Weight, kg & $101.5(13.9)$ & $88.5(13.2)$ & 0.026 \\
BMI, kg/m 2 & & & \\
Waist circumference, cm & $36.9(5.7)$ & $35.8(4.2)$ & 0.582 \\
Waist-to-hip ratio & $116.6(13.7)$ & $110.8(11.1)$ & 0.247
\end{tabular}


Fasting plasma glucose, $\mathrm{mg} / \mathrm{dL}$

HbA1c, \%

Total cholesterol, mg/dL

Triglycerides, mg/dL

HDL cholesterol, mg/dL

LDL cholesterol, mg/dL

Free fatty acids, $\mu \mathrm{Eq} / \mathrm{L}$

Visceral fat area, $\mathrm{cm}^{2}$
$123.2(38.5)$

$8.9(2.3)$

$164.1(27.5)$

$195(84.4)$

$34.4(7.3)$

$92(31.2)$

$614.9(190.8)$

$253(87)$
$128.8(35.1)$

0.709

$7.9(1.8)$

0.225

$181.7(46.2)$

0.288

175 (153.4)

0.071

$44.6(13.6)$

0.04

$102.8(37.8)$

0.458

$727.4(191.2)$

0.157

$258(121)$

0.918 
Subcutaneous fat area, $\mathrm{cm}^{2}$

Skeletal muscle mass, $\mathrm{kg}$

Body fat mass, $\mathrm{kg}$

Body fat percentage, $\%$

$\mathrm{L} / \mathrm{W}$ ratio

$\mathrm{U} / \mathrm{W}$ ratio

$\mathrm{L} / \mathrm{U}$ ratio

Physical activity level
380 (156)

$32.3(3.6)$

$41.6(13.3)$

$40.9(9.6)$

$0.18(0.03)$

$0.062(0.01)$

$2.88(0.34)$

$1.45(0.1)$
$371(96)$

0.855

$24.8(4.3)$

$<0.001$

$41.4(7.7)$

0.971

$47.5(3.4)$

0.019

$0.16(0.02)$

0.033

$0.062(0.01)$

0.911

$2.57(0.28)$

0.01

$1.46(0.1)$

0.744 
Basal metabolic rate, kcal/day

$1561(392)$

$1358(397)$

0.221

Locomotive NEAT score

$18.5(3.9)$

$16.4(4)$

0.193

3

Data are expressed as mean (SD). BMI, body mass index; HbA1c, hemoglobin A1c; HDL, high-density lipoprotein;

4 LDL, low-density lipoprotein; L/W ratio, the ratio of lower extremity muscle to body weight; U/W ratio, the ratio of 5 upper extremity muscle to body weight; L/U ratio, the ratio of lower to upper extremity muscle mass; NEAT, non6 exercise activity thermogenesis 
Table 2 (on next page)

Correlations of L/W ratio, $\mathrm{U} / \mathrm{W}$ ratio and $\mathrm{L} / \mathrm{U}$ ratio with physiological and biochemical parameters 
2 Table 2 Correlations of $\mathrm{L} / \mathrm{W}$ ratio, $\mathrm{U} / \mathrm{W}$ ratio and $\mathrm{L} / \mathrm{U}$ ratio with physiological and

3 biochemical parameters

\begin{tabular}{|c|c|c|c|c|c|c|}
\hline & \multicolumn{2}{|c|}{$\mathrm{L} / \mathrm{W}$ ratio } & \multicolumn{2}{|c|}{$\mathrm{U} / \mathrm{W}$ ratio } & \multicolumn{2}{|c|}{$\mathrm{L} / \mathrm{U}$ ratio } \\
\hline & $\begin{array}{l}\text { Correlation } \\
\text { coefficient }\end{array}$ & $p$ value & $\begin{array}{l}\text { Correlation } \\
\text { coefficient }\end{array}$ & $p$ value & $\begin{array}{l}\text { Correlation } \\
\text { coefficient }\end{array}$ & $p$ value \\
\hline Age, years & -0.233 & 0.251 & -0.348 & 0.082 & 0.215 & 0.29 \\
\hline BMI, $\mathrm{kg} / \mathrm{m}^{2}$ & -0.474 & 0.014 & -0.064 & 0.756 & -0.506 & 0.008 \\
\hline Waist circumference, $\mathrm{cm}$ & -0.458 & 0.019 & -0.013 & 0.948 & -0.523 & 0.006 \\
\hline Waist-to-hip ratio & -0.18 & 0.388 & 0.511 & 0.009 & -0.742 & $<0.001$ \\
\hline Triglycerides, mg/dl & 0.152 & 0.459 & -0.209 & 0.305 & 0.13 & 0.528 \\
\hline HDL cholesterol, mg/dL & -0.136 & 0.507 & -0.483 & 0.012 & 0.561 & 0.003 \\
\hline Free fatty acids, $\mu \mathrm{Eq} / \mathrm{L}$ & -0.526 & 0.006 & -0.391 & 0.049 & 0.047 & 0.821 \\
\hline Visceral fat area, $\mathrm{cm}^{2}$ & -0.034 & 0.869 & -0.074 & 0.72 & 0.05 & 0.807 \\
\hline
\end{tabular}




\begin{tabular}{lllllll} 
Subcutaneous fat area, $\mathrm{cm}^{2}$ & -0.526 & 0.006 & -0.230 & 0.259 & -0.331 & 0.099 \\
Body fat mass, $\mathrm{kg}$ & -0.571 & 0.002 & -0.261 & 0.198 & -0.327 & 0.101 \\
Body fat percentage, \% & -0.908 & $<0.001$ & -0.8 & $<0.001$ & -0.007 & 0.974 \\
PAL & 0.129 & 0.633 & -0.055 & 0.839 & 0.258 & 0.335 \\
Locomotive NEAT score & 0.634 & $<0.001$ & 0.387 & 0.051 & 0.223 & 0.273 \\
\hline
\end{tabular}

$4 \mathrm{~L} / \mathrm{W}$ ratio, the ratio of lower extremity muscle mass to body weight; $\mathrm{U} / \mathrm{W}$ ratio, the ratio of upper extremity muscle mass to body weight;

5 L/U ratio, the ratio of lower to upper extremity muscle; HDL, high-density lipoprotein; LDL, low-density lipoprotein; PAL, physical activity 6 level; NEAT, non-exercise activity thermogenesis 


\section{Table 3(on next page)}

Correlations of $\mathrm{L} / \mathrm{W}$ ratio, $\mathrm{U} / \mathrm{W}$ ratio and $\mathrm{L} / \mathrm{U}$ ratio with clinical parameters in men and women 
2 Table 3 Correlations of $\mathrm{L} / \mathrm{W}$ ratio, $\mathrm{U} / \mathrm{W}$ ratio and $\mathrm{L} / \mathrm{U}$ ratio with clinical parameters in men and

3 women

\begin{tabular}{|c|c|c|c|c|c|c|c|c|}
\hline & \multicolumn{4}{|c|}{ Men } & \multicolumn{4}{|c|}{ Women } \\
\hline & \multicolumn{2}{|c|}{$\mathrm{L} / \mathrm{W}$ ratio } & \multicolumn{2}{|c|}{$\mathrm{L} / \mathrm{U}$ ratio } & \multicolumn{2}{|c|}{$\mathrm{L} / \mathrm{W}$ ratio } & \multicolumn{2}{|c|}{$\mathrm{L} / \mathrm{U}$ ratio } \\
\hline & $\begin{array}{l}\text { Correlation } \\
\text { coefficient }\end{array}$ & $p$ value & $\begin{array}{l}\text { Correlation } \\
\text { coefficient }\end{array}$ & $p$ value & $\begin{array}{l}\text { Correlation } \\
\text { coefficient }\end{array}$ & $p$ value & $\begin{array}{l}\text { Correlation } \\
\text { coefficient }\end{array}$ & $p$ value \\
\hline Age, years & 0.032 & 0.931 & -0.435 & 0.208 & -0.16 & 0.553 & 0.259 & 0.332 \\
\hline BMI, $\mathrm{kg} / \mathrm{m}^{2}$ & -0.811 & 0.004 & -0.437 & 0.206 & -0.275 & 0.302 & -0.596 & 0.015 \\
\hline $\begin{array}{l}\text { Waist circumference, } \\
\mathrm{cm}\end{array}$ & -0.878 & 0.001 & -0.642 & 0.046 & -0.345 & 0.191 & -0.485 & 0.057 \\
\hline Waist-to-hip ratio & -0.392 & 0.297 & -0.76 & 0.017 & -0.387 & 0.138 & -0.773 & $<0.001$ \\
\hline Triglycerides, mg/dl & 0.024 & 0.948 & 0.296 & 0.407 & 0.222 & 0.409 & 0.139 & 0.606 \\
\hline HDL cholesterol, mg/dL & -0.147 & 0.685 & -0.386 & 0.271 & 0.152 & 0.574 & 0.643 & 0.007 \\
\hline Free fatty acids, $\mu \mathrm{Eq} / \mathrm{L}$ & -0.529 & 0.115 & -0.123 & 0.734 & -0.189 & 0.484 & -0.024 & 0.929 \\
\hline
\end{tabular}




\begin{tabular}{|c|c|c|c|c|c|c|c|c|}
\hline Visceral fat area, $\mathrm{cm}^{2}$ & -0.305 & 0.391 & -0.233 & 0.517 & 0.167 & 0.536 & 0.106 & 0.695 \\
\hline $\begin{array}{l}\text { Subcutaneous fat area, } \\
\mathrm{cm}^{2}\end{array}$ & -0.806 & 0.005 & -0.433 & 0.211 & -0.255 & 0.34 & -0.368 & 0.161 \\
\hline Body fat mass, kg & -0.925 & $<0.001$ & -0.564 & 0.09 & -0.125 & 0.644 & -0.32 & 0.227 \\
\hline Body fat percentage, $\%$ & -0.975 & $<0.001$ & -0.412 & 0.237 & -0.726 & 0.001 & -0.101 & 0.709 \\
\hline PAL & 0.651 & 0.234 & 0.038 & 0.951 & -0.062 & 0.855 & 0.279 & 0.406 \\
\hline $\begin{array}{l}\text { Locomotive NEAT } \\
\text { score }\end{array}$ & 0.621 & 0.055 & 0.381 & 0.278 & 0.618 & 0.011 & 0.335 & 0.205 \\
\hline
\end{tabular}

$4 \mathrm{~L} / \mathrm{W}$ ratio, the ratio of lower extremity muscle mass to body weight; $\mathrm{U} / \mathrm{W}$ ratio, the ratio of upper extremity muscle mass to body weight;

$5 \mathrm{~L} / \mathrm{U}$ ratio, the ratio of lower to upper extremity muscle; HDL, high-density lipoprotein; LDL, low-density lipoprotein; PAL, physical activity 6 level; NEAT, non-exercise activity thermogenesis 
Table 4 (on next page)

Comparison of age, sex, L/W ratio, U/W ratio, L/U ratio and locomotive NEAT score between the higher $\mathrm{BMI}$ group (BMI $\geq 35.9$ ) and lower $\mathrm{BMI}$ group $(\mathrm{BMI}<35.9$ ) 
2 Table 4 Comparison of age, sex, $\mathrm{L} / \mathrm{W}$ ratio, $\mathrm{U} / \mathrm{W}$ ratio, $\mathrm{L} / \mathrm{U}$ ratio and locomotive $\mathrm{NEAT}$

3 score between the higher BMI group $\left(B M I \geq 35.9 \mathrm{~kg} / \mathrm{m}^{2}\right)$ and lower BMI group $(\mathrm{BMI}<$ $4 \quad 35.9 \mathrm{~kg} / \mathrm{m}^{2}$ )

Higher BMI group Lower BMI group $\quad p$ value

Age, years

Sex (Men/Women)

L/W ratio

$\mathrm{U} / \mathrm{W}$ ratio

$\mathrm{L} / \mathrm{U}$ ratio

Physical activity level
$48.7(12.8)$

$6 / 7$

$0.16(0.02)$

$0.06(0.01)$

$2.57(0.28)$

$1.47(0.1)$
$52.7(13.8)$

$4 / 9$

$0.18(0.03)$

$0.06(0.01)$

$2.88(0.34)$

0.016

$1.45(0.1)$

0.68 
Data are expressed as mean (SD). L/W ratio, the ratio of lower extremity muscle to body weight; U/W ratio, the ratio of 6 upper extremity muscle to body weight; L/U ratio, the ratio of lower to upper extremity muscle mass; NEAT, non-

7 exercise activity thermogenesis

$8 *$ chi-square test was performed. 